\title{
Examples of electromagnetic field (50-100 kHz) emissions from smart meters in Finland
}

\author{
R. Pääkkönen ${ }^{1}$, M. Lundström ${ }^{2}$, J. Mustaparta ${ }^{3}$ and L. Korpinen ${ }^{4 \star}$ \\ ${ }^{1}$ Finnish Institute of Occupational Health, P.O. Box 486, 33101 Tampere, Finland. \\ 2 Tampereen Sähköverkko Oy, Voimakatu 11, 33100 Tampere Finland. \\ 3 Turku Energia Sähköverkot Oy, Linnankatu 65, 20100 Turku, Finland. \\ ${ }^{4}$ Environmental Health, Tampere University of Technology, P.O. Box 692, 33101 Tampere, Finland.
}

Received 4 August 2014 - Accepted 5 February 2015

\begin{abstract}
The aim of this study was to collect example measurements of electromagnetic field exposure via smart meters for cable-transmitted $(50-100 \mathrm{kHz})$ signal emissions in a meter room in Finland. We measured different smart meters and different concentrators. The magnetic fields in various situations on the meter surface ranged from $0.1-2.2 \mu \mathrm{T}$. The measured values were less than $10 \%$ of the ICNIRP reference level (RL) for the public $(27 \mu \mathrm{T}$ for those frequencies). When the typical spectator distance is considered, the ratio is even smaller: less than $1 \%$ of the RL. The electric fields (EFs) were between 0.2 and $2.5 \mathrm{~V} \mathrm{~m}^{-1}$ (RL $83 \mathrm{~V} \mathrm{~m}^{-1}$ for the public). In comparing the measured EF values with the RLs, the values are less than $3 \%$. Based on our measurements, there is no need to improve the sheltering of the meters from the public.
\end{abstract}

Keywords: magnetic field / electric field / smart meter

\section{Introduction}

Smart meters are common in metering electricity in Finland. Principally, these meters can be divided into two categories when considering electromagnetic radiation emission (Britton et al., 2013; Tell et al., 2013). In Finland, these smart meters most often send information or communicate using either a radio frequency (RF) (800-3000 MHz) aerial signal to masts, for example GRPS (General Packet Radio Service), or a Power-Line Communication (PLC) signal through cables in the $50-100 \mathrm{kHz}$ frequency range.

A global smart meter system between the electricity provider and the customer has been developed, where smart meters send information to electricity companies through cables (PLC, frequency $50-100 \mathrm{kHz}$ ) or through the mobile phone network (800-2000 MHz). These smart meters are usually situated outside or at the entrance of single family houses, or in a locked room in buildings (Lienert, 2014).

Usually in Finland, smart meters are inserted in technical spaces of apartment buildings as a group containing as many meters as there are families (Figure 1). In a single-family house, usually there is only one smart meter inside or outside of the house. The concentrator, which collects the data of several smart meters, is located inside a $10-20 \mathrm{kV} / 400 \mathrm{~V}$ substation.

\footnotetext{
^ leena.korpinen@tut.fi
}

The ICNIRP has published electric and magnetic field RLs concerning the public, and the values at $50-100 \mathrm{kHz}$ are $83 \mathrm{~V} \mathrm{~m}^{-1}$ for EFs and $27 \mu \mathrm{T}$ for magnetic flux density (MFD) (ICNIRP, 2010). However, most discussions on adverse effects on health in Finland and elsewhere focused on smart meters that use RF signals with cellular phone masts. On the other hand, in Finland, most urban areas use cable reading smart meters for frequencies of $50-100 \mathrm{kHz}$.

The aim herein was to present example measurements of EMF exposure to smart meters for cable-transmitted $(50-100 \mathrm{kHz})$ signal emissions in a meter room in Finland. This is a pilot study and will be used to develop further measurements.

\section{Measurement methods}

We used the MF meter MFM 3000 - the separate probe version - by Combinova (frequency range $40-100 \mathrm{kHz}$ and $10 \mathrm{nT}-10 \mathrm{mT}$ ) and video recording with RMS values and spectrum (Samsung Galaxy S III smartphone). We measured EF values using a single-direction Holaday Industries meter 3603 (2-300 kHz and $0.2-2000 \mathrm{~V} \mathrm{~m}^{-1}$ ), where we assessed vectors pointing directly opposite from the smart meter. The distance was either at the surface of the meter or $30 \mathrm{~cm}$ directly from the meter (worker position).

Figure 1 shows an example of the MFM 3000 meter measurements. We measured in real conditions with active 


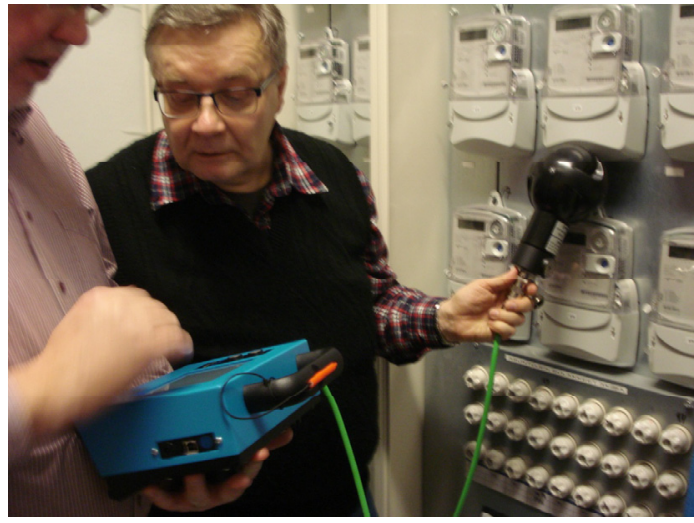

Figure 1. Example of MFM 3000 meter measurements.

consumer smart meters. Our measurements aimed to capture real exposure and emission situations, not in a laboratory environment. The meter reading process is very short, only about 20 s. Moreover, we collaborated with electrical companies, who dispatched employees to assist us. Once the measurement sensor was in position, these officers read that particular meter from a distance of $30 \mathrm{~cm}$. We recorded instantaneous maximum EF or MF values. We communicated through mobile phones to obtain real responses and be certain that we measured the reading communication. The RF signals from the mobile phones did not affect EF and MF sensor performance because conversation always occurred at further distances and the frequencies were different. We also repeated these readings several times in each case.

Figure 2 shows an example of spectrum analysis (Fast Fourier spectrum, FFT; $5 \mathrm{~Hz}$ to $100 \mathrm{kHz}$, but analysis on a frequency range of $40-100 \mathrm{kHz}$ ), where the peak from the smart meter was $0.29 \mu \mathrm{T}$ at a frequency of $83 \mathrm{kHz}$. We checked that there were no other sources at frequencies of $50-100 \mathrm{kHz}$.

The emitted fields reduced rapidly in strength with increasing distance within the first few centimetres of the meters. Therefore, as the measurement sensors (electric and magnetic) used in this work have dimensions of about $10 \mathrm{~cm}$, the field strength varies appreciably over their volume when a measurement is made at the meter surface. Good practice usually dictates that a measurement sensor of dimension $10 \mathrm{~cm}$ should not be used closer to a source than around $30 \mathrm{~cm}$ in order to make robust measurements. However, for measurement sensitivity reasons, we had to measure as close as possible.

\section{Results}

We measured two cases: (1) smart meters in technical spaces of buildings (Iskraemeco meters and Landis+Gyr meters), and (2) concentrators in substations (Landis+Gyr EMPC100 v7.81 and ISKRA P2LPC-DLMS concentrators).

\section{Case 1A: Iskraemeco meters}

With the MFM 3000 meter (frequency range 40-100 kHz), we measured four identical meters at different places on the

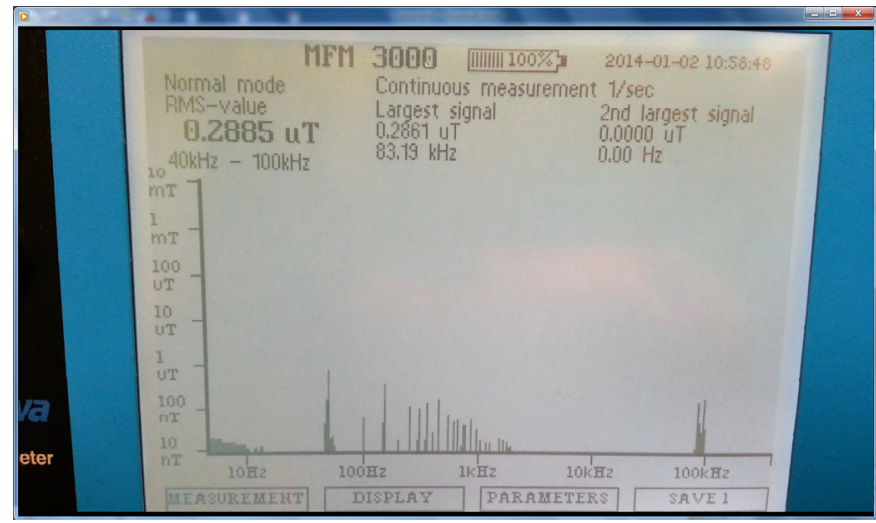

Figure 2. Example from an instantaneous frequency spectrum, where a smart meter emits frequencies at about $80-90 \mathrm{kHz}$. MFD is $0.29 \mu \mathrm{T}$.

meter surface : (1) the maximum value was about $0.10 \mu \mathrm{T}$; (2) the maximum value was $0.14 \mu \mathrm{T}$; (3) the maximum value was $0.18 \mu \mathrm{T}$, and (4) the maximum value was $0.16 \mu \mathrm{T}$. In addition, we measured values of 1.5 to $2.5 \mathrm{~V} \mathrm{~m}^{-1}$ using the Holaday Industries meter 3603.

We also studied how the distances influence the MFs. When the distance was $30 \mathrm{~cm}$, the MF was $0.021 \mu \mathrm{T}$ (the same height as the meter), and when the distance was $50 \mathrm{~cm}$, the MF was less than $10 \mathrm{nT}$. The EF was $0.22 \mathrm{~V} \mathrm{~m}^{-1}$ at the distance of $30 \mathrm{~cm}$ (during the active phase) and the background value was $0.2 \mathrm{~V} \mathrm{~m}^{-1}$.

\section{Case 1B: Landis+Gyr meters}

The MFs had different measurements: the first meter $0.24 \mu \mathrm{T}$ on the surface, and the second meter $0.34 \mu \mathrm{T}$ on the surface. The EF was below $0.28 \mathrm{~V} \mathrm{~m}^{-1}$ when the distance was $30 \mathrm{~cm}$.

\section{Case 2: Concentrators inside MV/LV substations}

Two concentrators (Iskraemeco ISKRA P2LPC-DLMS and Landis+Gyr EMPC100 v7.81) were used. We made three measurements in different substations: (1) only Iskraemeco, (2) only Landis+Gyr, and (3) both Iskraemeco and Landis+Gyr. We obtained the following results at the surface of the meters:

(1) only Iskraemeco: the maximum magnetic field was $2.01 \mu \mathrm{T}$

(2) only Landis+Gyr: the maximum magnetic field was $0.41 \mu \mathrm{T}$

(3) both Iskraemeco and Landis+Gyr: the maximum MF was $2.20 \mu \mathrm{T}$.

\section{Discussion}

This article presents the first EMF measurements for PLC smart meters. The measured MFDs in various situations on the meter surface varied from $0.1-2.2 \mu \mathrm{T}$, and, again, the ICNIRP $\mathrm{RL}$ is $27 \mu \mathrm{T}$ for those frequencies. Therefore, the measured 
values were less than $10 \%$ of the RL. When the usual spectator distance is considered, the ratio is even smaller, usually less than $1 \%$ of the recommended field value. When EF values were considered, they varied between 0.2 and $2.5 \mathrm{~V} \mathrm{~m}^{-1}$, which is also less than $3 \%$ of the RL.

For the concentrators, the surface values were somewhat higher, around $2 \mu \mathrm{T}$ compared with about $0.2 \mu \mathrm{T}$ for the usual smart meters, but both values are low compared with the RL for the public. When considering the attenuation at $30 \mathrm{~cm}$, the MFD was about $10 \%$ compared with the surface values.

Potentially, background EMFs could disturb the measurements in real conditions, if the measurements are performed in broadband. For example, when there are HUB stations, antenna amplifiers, or other electrical equipment in the same room, their fields can be higher than the fields emitted by the smart meters. Furthermore, many EMF meters have a broadband frequency measurement range, and thus a broadband measurement can show field values that are not caused by these smart meters. In our case, we always checked that the background values were not disturbing the measurement values; we used a MF meter frequency analyser and a small commercial frequency counter (in some cases) to ensure that we were really measuring the smart meter emissions.

The smart meters do not communicate continuously with the reading system. During the measurements, we forced the meters to communicate, and during that time, we video recorded the values on the meter. The reading took about $20 \mathrm{~s}$, and if occurring, for example, once an hour, it is very probable that the person near the meters is most often farther than $50 \mathrm{~cm}$ from the meters. If one is trying to measure these fields without electrical company assistance, it is possible that these fields remain unseen. We experienced this when we tried to measure fields with logging devices that had 5-10-s sampling periods and perhaps a dead time between active samplings.

When considering this information, improving the sheltering of meters from the public is unnecessary, as only authorised personnel are typically granted access to the meter room, and the measured levels are lower than the reference levels of the European Recommendation $\left(6.25 \mu \mathrm{T}\right.$ and $\left.87 \mathrm{~V} \mathrm{~m}^{-1}\right)$ (Council recommendation, 1999).

\section{Conclusion}

In this pilot study the MF and EF values at frequencies of $50-100 \mathrm{kHz}$ were low compared with the ICNIRP (2010) RLs for the public, usually at the meter surface and less than $1 \%$, with the exception of concentrators, where the highest values were less than $10 \%$ of the RL. However, if we consider the situation at a distance of $0.5 \mathrm{~m}$ from the meters, the field values are insignificant compared with the reference value. For a possible larger study, measurement technology should be developed. This work received very low values. However, if a more sophisticated study is conducted, we would recommend that smaller sensors are used. We also recommend not using broadband measurements, but checking the frequency measured. Finally, this pilot study highlights the need for time correlation between EMF measurement of the smart meter and data reading of the smart meter.

Acknowledgements. The project was financed by the Association for Promotion of Electrical Safety (STEK ry).

\section{References}

Britton T., Stewart R., O'Halloran K. (2013) Smart metering: enabler for rapid and effective post meter leakage identification and water loss management, J. Cleaner Production 54, 166-176.

Council recommendation 1999/519/EC (1999) on the limitation of exposure of the general public to electromagnetic fields $(0 \mathrm{~Hz}$ to $300 \mathrm{GHz}), 12$ July 1999.

ICNIRP (2010) Guidelines for limiting exposure to time varying electric and magnetic fields (1 Hz-100 kHz), Health Phys. 99, 818836.

Lienert F. (2014) The GB smart meter roll-out. In: European Conference on Smart Metering Deployment in the EU, 26 June 2014, Brussels.

Tell R., Kavet R., Mezei G. (2013) Characterization of radiofrequency field emissions from smart meters, J. Exposure Sci. Environ. Epidemiol. 23, 549-553. 